\title{
Collective impact of chronic medical conditions and poverty on perinatal mental illness: population-based cohort study
}

\author{
Mary-Rose Faulkner, Lucy C. Barker, Simone N. Vigod, \\ Cindy-Lee Dennis, Hilary K Brown
}

\begin{abstract}
Version Accepted Manuscript
Citation Faulkner M, Barker LC, Vigod SN, et al Collective impact of chronic (published version) medical conditions and poverty on perinatal mental illness: populationbased cohort study J Epidemiol Community Health 2020;74:158-163.

Copyright / License (C) Authors (or their employer(s)) 2020

Publisher's Statement This article has been accepted for publication in the Journal of Epidemiology and Community Health, 2020 following peer review, and the Version of Record can be accessed online at bttp://dx.doi.org/10.1136/jech-2019-212714
\end{abstract}

How to cite TSpace items

Always cite the published version, so the author(s) will receive recognition through services that track citation counts, e.g. Scopus. If you need to cite the page number of the author manuscript from TSpace because you cannot access the published version, then cite the TSpace version in addition to the published version using the permanent URI (handle) found on the record page.

This article was made openly accessible by $U$ of $T$ Faculty. Please tell us how this access benefits you. Your story matters. 
The collective impact of chronic medical conditions and poverty on perinatal mental illness: A population-based cohort study

Authors: Mary-Rose Faulkner, MPH ${ }^{1,2}$; Lucy Barker MD FRCPC ${ }^{2,3}$; Simone N. Vigod, MD MSc FRCPC ${ }^{2-4}$; Cindy-Lee Dennis, PhD ${ }^{3,5,6}$; Hilary K. Brown, PhD ${ }^{1-3,7}$

Affiliations: ${ }^{1}$ Dalla Lana School of Public Health, University of Toronto, Toronto, Canada;

${ }^{2}$ ICES, Toronto, Canada; ${ }^{3}$ Department of Psychiatry, University of Toronto, Toronto, Canada;

${ }^{4}$ Women's College Research Institute, Women's College Hospital, Toronto, Canada; ${ }^{5}$ Lawrence S. Bloomberg Faculty of Nursing, University of Toronto, Toronto, Canada; ${ }^{6} \mathrm{Li} \mathrm{Ka}$ Shing Knowledge Institute, St. Michael's Hospital, Toronto, Canada; ${ }^{7}$ Interdisciplinary Centre for Health \& Society, University of Toronto Scarborough, Toronto, Canada.

Contact information for the corresponding author: Hilary K. Brown, Interdisciplinary Centre for Health \& Society, University of Toronto Scarborough, 1265 Military Trail, Toronto, Ontario, Canada, M1C 1A4; +1 416208 2239; hk.brown@utoronto.ca 


\begin{abstract}
Background: Chronic medical conditions (CMC) and poverty commonly co-occur and, while both have been shown to independently increase perinatal mental illness risk, their collective impact has not been examined.
\end{abstract}

Methods: This population-based study included 853,433 Ontario (Canada) women with a singleton livebirth and no recent mental health care. CMCs were identified using validated algorithms and disease registries, and poverty was ascertained using income quintile. Perinatal mental illness was defined as a health care encounter for a mental health or substance use disorder in pregnancy or the first year postpartum. Modified Poisson regression was used to test the independent impacts of CMC and poverty on perinatal mental illness risk, adjusted for covariates, and additive interaction between the two exposures was assessed using the relative excess risk due to interaction (RERI) and synergy index (SI).

Results: CMC and poverty were each independently associated with increased risk for perinatal mental illness (CMC vs. no CMC exposure: $19.7 \%$ vs. $15.5 \%$, adjusted relative risk [aRR] 1.21, $95 \%$ confidence interval $[\mathrm{CI}] 1.20,1.23$; poverty vs. no poverty exposure: $16.7 \%$ vs. $15.5 \%$, aRR $1.06,95 \%$ CI 1.05, 1.07). However, measures of additive interaction for the collective impact of both exposures on perinatal mental illness risk were not statistically significant (RERI 0.02, 95\% CI -0.01, 0.06; SI 1.09, 95\% CI 0.95, 1.24).

Conclusion: $\mathrm{CMC}$ and poverty are independent risk factors for perinatal mental illness and should be assessed as part of a comprehensive management program that includes prevention strategies and effective screening and treatment pathways. 


What is already known on this subject
Previous studies have reported that CMC and poverty independently increase the risk of
perinatal mental illness. However, no studies have examined the collective impact of CMC
and poverty on perinatal mental illness risk.
What this study adds
This is the first study to examine the collective impact of CMC and poverty on perinatal
mental health. While both CMC and poverty independently increased perinatal mental illness
risk, the collective impact of these factors was not greater than the sum of their individual
effects, contrary to our hypothesis of a synergistic effect. However, given that one in 20
women experience co-occurring CMC and poverty, our findings suggest that perinatal mental
health programs that promote preventive strategies in high-risk women, including those with
CMC and poverty, are warranted.




\section{Introduction}

The prevalence of chronic medical conditions (CMC) such as hypertension, diabetes, and asthma in pregnant women has risen $40 \%$ in the past 10 years, ${ }^{1}$ now impacting $20 \%$ of expectant mothers. ${ }^{2}$ One in four pregnant women live in poverty. ${ }^{3}$ Poverty and CMC frequently co-occur, ${ }^{4}$ and both contribute to enhanced stress in the perinatal period. ${ }^{5,6}$ Yet, the collective impact of CMC and poverty on perinatal mental health is unknown. Perinatal mental illness has substantial public health importance: one in five women have a mood or anxiety, psychotic, or substance use disorder in pregnancy or postpartum, ${ }^{7}$ and such conditions can have long-term negative effects on women and children. ${ }^{8,9}$ Knowledge of the collective impact of CMC and poverty on perinatal mental health could direct evidence-informed organization of care to target vulnerable families.

CMCs disproportionately affect women living in poverty, even in nations with universal health care and strong social policies and programs. In a Canadian cross-sectional study, the odds of type 2 diabetes were higher for women with the lowest household income than those with the highest [odds ratio (OR) 2.75; 95\% confidence interval (CI) 2.24, 3.37]. ${ }^{10}$ Another Canadian study showed that markers of poverty were associated with elevated odds of heart attack [OR 1.93; 95\% CI 1.27-2.93] and chronic lung disease [OR 1.48; 95\% CI 1.19, 1.83]. ${ }^{11}$ Similar results have been found in areas with comparable health systems, including Australia and the UK, ${ }^{12-14}$ and in the US, where most health care is privatized. ${ }^{4,14,15}$ The mechanisms connecting CMC and poverty are complex; individuals living in poverty are susceptible to obesity, ${ }^{16}$ smoking, ${ }^{17}$ poor exercise and diet, ${ }^{18,19}$ and reduced health care access, ${ }^{4}$ all of which could elevate CMC risk. CMC might also lead to poverty by impeding ability to hold employment. ${ }^{20}$ While prior research has shown that both CMC and poverty independently increase perinatal mental illness risk, no studies have examined their collective impact. A meta-analysis 
of 12 studies reported that women with CMC had moderately higher odds of perinatal mental illness [pooled adjusted OR 1.43; 95\% CI 1.25, 1.63], possibly due to insufficient sleep, pain, neuroendocrine effects of certain CMCs, or common genetic factors. ${ }^{5}$ A meta-analysis of 14 studies showed that lower family income was associated with increased postpartum depression prevalence [Cohen's $d-0.14 ; 95 \%$ CI $-0.21,-0.08],{ }^{6}$ possibly due to social isolation and barriers to care. ${ }^{21}$ Women with $\mathrm{CMC}$ who are living in poverty could experience excess risk for perinatal mental illness due to poorer disease management. Given the common co-occurrence of CMC and poverty, there is a need to examine their potential synergistic impact on perinatal mental illness.

This paper aims to (1) estimate the prevalence of co-occurring CMC and poverty in pregnant women and (2) examine their collective impact on perinatal mental illness risk.

\section{METHODS}

\section{Study Design}

These aims were investigated in a population-based cohort in Ontario, Canada. Ontario's universal health care system covers the costs of medically necessary health care for all Ontario residents. We included 15 to 49 -year-old women with a hospital delivery of a singleton livebirth conceived between April 1, 2005 and March 31, 2015. To identify new-onset or relapse perinatal mental illness, women were excluded if they had mental health care encounters $<24$ months before conception. Women were observed throughout pregnancy and for one year after delivery. The use of data was authorized under section 45 of Ontario's Personal Health Information Protection Act, which does not require review by a Research Ethics Board.

\section{Data Sources}


Health administrative datasets were accessed at ICES (formerly the Institute for Clinical Evaluative Sciences, Toronto, Ontario), a not-for-profit, independent agency that stores data on the use of the health care system. The following databases were linked at the individual level using an encrypted identification number and analyzed at ICES: the MOMBABY dataset (maternal-newborn records for $>98 \%$ of hospital deliveries ${ }^{22}$ ), the Ontario Health Insurance Plan database (physician visits), the Canadian Institute for Health Information Discharge Abstract Database (hospital admissions), the National Ambulatory Care Reporting System (emergency department visits), the Ontario Mental Health Reporting System (hospitalizations in institutions with designated mental health beds), the Registered Persons Database (demographics), and the IRCC Permanent Resident Database (immigrant status). Physician billing claims, primary diagnoses in hospital data, and demographics have been shown to be valid. ${ }^{23}$

\section{Exposures}

Algorithms and disease registries validated against clinical diagnosis ${ }^{24-26}$ were used to identify $16 \mathrm{CMCs}$ that are common in reproductive-aged women and could have an adverse impact on pregnancy (Supplementary Table S1). ${ }^{1,2}$ Each CMC required a certain number of physician visits, emergency department visits, or hospital admissions in a specific interval before conception. We did not include conditions developing after conception (e.g., gestational diabetes). Women were classified as exposed if they had $\geq 1 \mathrm{CMCs}$; women without these CMCs were unexposed. Poverty was assessed using neighbourhood-level income. Neighbourhoods were defined using census dissemination $\operatorname{areas}^{27}$ based on maternal postal code at conception. Research has shown that the use of neighbourhood-level income to identify poverty is a suitable alternative to individual-level data, when the latter are unavailable. ${ }^{27}$ In line with previous 
studies, ${ }^{28}$ income quintiles were dichotomized such that women in the bottom 2 quintiles were considered to be exposed to poverty, and women in the upper 3 quintiles were unexposed.

\section{Outcome}

Perinatal mental illness was identified by $\geq 1$ visits with a family physician or psychiatrist, emergency department visits, or hospital admissions for mental illness in pregnancy or within 1 year postpartum. Secondary outcomes evaluated timing (i.e., prenatal or postpartum), diagnosis (i.e., mental health disorder or substance use disorder), and type of mental health care (i.e., ambulatory or acute). Categorizations for timing were based on the first health care encounter in the follow-up period, and those for diagnosis and type of mental health care were made based on all encounters. Since women with a recent history of mental health care were excluded, perinatal mental health care encounters represented a new episode or a new-onset mental illness.

\section{Covariates}

Covariates were maternal age, parity, rurality (defined by the Rurality Index of Ontario as rural or urban based on indicators such as presence of health care providers, travel time to different care levels, and weather ${ }^{29}$ ), immigrant status, and past history of mental health care (determined by a mental health care encounter $>24$ months before pregnancy).

\section{Analysis}

We described the prevalence of co-occurring CMC and poverty. Baseline characteristics of the cohort were then described using frequencies and percentages, stratified by CMC and poverty status: both $\mathrm{CMC}$ and poverty, only $\mathrm{CMC}$, only poverty, and neither CMC nor poverty. 
Modified Poisson regression was used to compute relative risks (RR) of perinatal mental illness for CMC and poverty separately; ${ }^{30}$ generalized estimating equations accounted for women with multiple deliveries in the study period. ${ }^{31}$ The adjusted model included age, parity, rurality, immigrant status, and past history of mental health care. ${ }^{5,6} \mathrm{~A} \mathrm{CMC}$-poverty interaction was then added to the adjusted model; this was used to calculate measures of additive interaction. Additive interaction tests if the joint effect of two exposures is greater than the sum of their individual effects and more accurately reflects synergism between two exposures than multiplicative interaction. ${ }^{32}$ We measured the relative excess risk due to interaction (RERI, the part of the total effect that is due to interaction, $\left.R_{11}-R_{10}-R_{01}+1\right)$ and synergy index (SI, the ratio between the joint effect of two exposures and their individual effects, $\left.\left[R_{11}-1\right] /\left[R_{10}+R_{01}-2\right]\right) .{ }^{32} A$ RERI of 0 means no interaction, while RERI >0 means positive interaction; a SI of 1 means no interaction, while $\mathrm{SI}>1$ means positive interaction. ${ }^{32}$ We also plotted the values for $\mathrm{RR}_{11}, \mathrm{RR}_{10}$, and $\mathrm{RR}_{01}$ so that the presence or absence of additive interaction could be visualized.

We conducted several sensitivity analyses. First, we tested the impact of the outcome definition on the results by examining perinatal mental illness by timing, diagnosis, and type of mental health care encounter. Second, we tested the impact of exposure definitions on the results by examining multiple CMCs, $1 \mathrm{CMC}$, and none separately, the lowest income quintile versus all others, and all 5 income quintiles separately. SAS Enterprise v. 9.3 was used for analysis.

\section{Results}

\section{Main Results}

In the cohort ( $n=853,433$, Figure 1$), 11.7 \%$ of women had $\geq 1 \mathrm{CMCs}$, and $41.1 \%$ were in the lowest two income quintiles; the prevalence of co-occurring $\mathrm{CMC}$ and poverty was 5.0\%. 
Women with co-occurring CMC and poverty were younger than those with neither CMC or poverty and were more likely to be a refugee or immigrant and have a past history of mental health care (Table 1). Compared to women with CMC only, women with co-occurring CMC and poverty were younger and more likely to be refugees or immigrants, but less likely to have a past history of mental health care. Compared to women with poverty only, women with co-occurring CMC and poverty tended to be older and more likely to have a past history of mental health care.

Chronic medical conditions and poverty were each associated with increased perinatal mental illness risk before and after adjustment (Table 2). Among women with $\geq 1 \mathrm{CMCs}, 19.7 \%$ experienced a perinatal mental illness, compared to $15.5 \%$ of those without a CMC [adjusted RR $1.21,95 \%$ CI $1.20,1.23]$. Likewise, among women living in poverty, $16.7 \%$ had a perinatal mental illness, compared to $15.5 \%$ of those not living in poverty [adjusted RR $1.06,95 \% \mathrm{CI}$ 1.05-1.07]. When examining the collective influence of CMC and poverty on perinatal mental illness risk, the greatest mental illness risk was seen in women with co-occurring CMC and poverty, followed by CMC only, poverty only, and neither CMC nor poverty (Figure 2). However, measures of additive interaction were not statistically significant [RERI 0.02, 95\% CI 0.01, 0.06; SI 1.09, 95\% CI 0.95, 1.24], demonstrating that CMC and poverty did not act synergistically in their impact on perinatal mental illness risk.

\section{Sensitivity Analyses}

When examining perinatal mental illness by timing, the greatest risk for prenatal and postpartum mental illness was seen in women with co-occurring CMC and poverty (Figure S1). However, measures of additive interaction were not statistically significant for prenatal [RERI 0.03, 95\% CI -0.03, 0.09; SI 1.10, 95\% CI 0.90, 1.34] or postpartum mental illness [RERI 0.02, 
95\% CI -0.03, 0.07; SI 1.08, 95\% CI 0.91, 1.29]. When examining diagnosis, the greatest risk for mental health disorders and substance use disorders was seen in women with co-occurring CMC and poverty (Figure S2). Yet, measures of additive interaction were non-significant for mental health disorders [RERI 0.02, 95\% CI -0.01, 0.06; SI 1.08, 95\% CI 0.95, 1.24] and substance use disorders [RERI 0.05, 95\% CI -0.32, 043; SI 1.04, 95\% CI 0.78, 1.39]. When examining type of mental health care encounter, the greatest risk for ambulatory and acute care was seen in women with co-occurring CMC and poverty (Figure S3). However, measures of additive interaction were non-significant for ambulatory [RERI 0.02, 95\% CI -0.02, 0.06; SI 1.08, 95\% CI 0.94, 1.25 ] and acute care [RERI $0.07,95 \%$ CI -0.13, 0.26; SI 1.09, 95\% CI 0.86, 1.37].

Next, we examined CMCs according to the number of conditions. The greatest risk for perinatal mental illness was seen in women with co-occurring CMC and poverty, with similar patterns in women with $\geq 2 \mathrm{CMCs}$ and those with one CMC (Figure S4). However, measures of additive interaction were non-significant for $\geq 2$ CMCs [RERI -0.08, 95\% CI -0.21, 0.04; SI 0.82, 95\% CI 0.60, 1.12] and one CMC [RERI 0.03, 95\% CI -0.01, 0.07; SI 1.13, 95\% CI 0.98, 1.31$].$

When we defined poverty as being in the lowest income quintile, relative to all others, the greatest risk of perinatal mental illness was seen in women with co-occurring CMC and poverty (Figure S5), but measures of additive interaction were non-significant [RERI 0.02, 95\% CI -0.03, 0.06; SI 1.07, 95\% CI 0.92, 1.24]. When we examined each income quintile separately, perinatal mental illness risk increased as quintile decreased, with the greatest risk in women in the lowest quintile with co-occurring CMC (Figure S6). Additive interaction measures were non-significant for CMC and quintile 1 [RERI 0.03, 95\% CI -0.03, 0.09; SI 1.09, 95\% CI 0.90, 1.31], 2 [RERI 0.02, 95\% CI -0.04, 0.09; SI 1.09, 95\% CI 0.88, 1.35], 3 [RERI 0.00, 95\% CI -0.07, 0.06; SI 0.99, 95\% CI 0.78, 1.25], and 4 [RERI 0.01, 95\% CI -0.05, 0.07; SI 1.04, 95\% CI 0.80, 1.34]. 


\section{Discussion}

This is the first study to examine the collective impact of CMC and poverty on perinatal mental health. Both CMC and poverty independently increased perinatal mental illness risk. While risk was greatest among women with co-occurring CMC and poverty, the collective impact of these factors was not greater than the sum of their individual effects, contrary to our hypothesis of a synergistic effect. However, given that one in 20 women experienced cooccurring CMC and poverty, our findings suggest that perinatal mental health programs that promote preventive strategies in high-risk women, including those with CMC and poverty, is warranted to compliment evidence-based screening and treatment pathways.

Prior research supports independent impacts of CMC and poverty on perinatal mental illness risk. ${ }^{5,6}$ In a meta-analysis of 12 studies, Brown et al. ${ }^{5}$ found that women with CMC had higher odds of perinatal mental illness [pooled adjusted OR 1.43; 95\% CI 1.25, 1.63]. Findings were consistent across the perinatal period and by specific diagnosis of perinatal mental illness and type of CMC. ${ }^{5}$ Our finding of an independent impact of $\mathrm{CMC}$ on perinatal mental health is consistent with these studies. In a meta-analysis of 14 studies, O'Hara et al. ${ }^{6}$ found that lower family income was associated with increased postpartum depression prevalence [Cohen's $d$ $0.14 ; 95 \%$ CI $-0.21,-0.08]$. However, the effect size was smaller than history of mental illness, poor social support, and stressful life events. ${ }^{6}$ These findings are consistent with ours; while neighbourhood-level income was associated with perinatal mental illness, the risk magnitude was small. Our study is unique in its examination of the collective impacts of CMC and poverty; our methods should be replicated in studies with individual-level measures of poverty.

Several explanations have been posited for the perinatal mental health impacts of CMC and poverty. Women with CMC may experience stress from disease management, insufficient 
sleep, and pain. ${ }^{33}$ There is also evidence that autoimmune conditions have neuroendocrine effects, ${ }^{34}$ while common genetic factors underlie depression and diabetes. ${ }^{35}$ Low social support and barriers to accessing care have been hypothesized to explain the association between poverty and perinatal mental illness. ${ }^{21}$ We hypothesized that $\mathrm{CMC}$ and poverty together would have a synergistic impact on perinatal mental health. Poverty could exacerbate CMC complications, and CMC could further isolate individuals living in poverty, with co-occurring factors having a greater impact on perinatal mental health than either of them separately. However, while risk for perinatal mental illness was greatest in women with co-occurring $\mathrm{CMC}$ and poverty, additive interaction was not statistically significant. The absence of additive interaction may be explained by a ceiling effect with respect to risk from multiple exposures, the use of neighbourhood-level measures of poverty, or the exclusion of women with recent mental health care.

\section{Limitations}

Strengths of this study include the use of population-based data from our universal health care system and validated algorithms and registries to identify CMC. However, we were unable to capture the heterogeneity in how CMCs could impact an individual's experience, for example via differences in the nature or severity of the condition. Further, while Ontario's universal health care plan covers medically necessary physician and hospital care, prescription medication costs are covered by a combination of private insurance and a publicly funded drug plan for individuals with disabilities, on social assistance, or with high prescription costs relative to income. Such factors could influence the independent association between CMC and perinatal mental illness and how CMC interacts with poverty. Individual-level measures of poverty were unavailable. While prior studies have shown that neighbourhood-level income is a suitable 
alternative to individual-level data, ${ }^{27}$ individuals may have incomes that are not congruent with neighbourhood averages, particularly in urban neighbourhoods undergoing rapid gentrification. ${ }^{27}$ Also, wellness might be decided collectively by individual and neighbourhood factors. ${ }^{36}$ These factors may have reduced our ability to measure the impact of poverty on perinatal mental health. Perinatal mental illness was defined in physician visits, emergency department visits, or hospital admissions. Women with perinatal mental illness who did not receive care in these contexts (e.g., those with untreated mental illness or those seeking care elsewhere) could not be counted as having the outcome. This might have resulted in a lower incidence of perinatal mental illness in the cohort than the true incidence in Ontario, and this bias may be greater in marginalized groups. It is also possible that women with only one physician visit for mental illness could represent false-positives if the reason for the visit was assessment rather than diagnosis or treatment. Such misclassification is less likely in emergency department visits and hospitalizations, which represent severe mental illness. Our findings were similar when we examined ambulatory and acute mental health care separately.

Obesity, social isolation, and stressful life events are crucial to consider in the context of $\mathrm{CMC}$, poverty, and perinatal mental illness but were not measured in our datasets. Other variables, such as past history of mental illness may have been measured incompletely in new immigrants to Canada as well as women who previously lived in a different Canadian province. Therefore, residual confounding could explain some of our results.

\section{Conclusion}

Our findings have implications for mental health care for women in the perinatal period. Women with CMC and poverty, and particularly those with co-occurring factors, may benefit 
from being included in mental health prevention and intervention programs. Since women with CMC are already well-connected with the health care system around the time of pregnancy, such resources could be embedded in obstetrical settings, with particular attention to the unique needs of women also living in poverty. Since both groups have high rates of obesity, smoking, and poor exercise and nutrition, and these may also be associated with perinatal mental health, these modifiable factors could be targeted as part of a comprehensive approach to optimizing perinatal mental health that starts preconceptionally. 
Acknowledgments: We gratefully acknowledge the Canadian Institutes of Health Research for their support of this study through their Project Grant program (376290). The funding agency had no role in the design and conduct of the study; collection, management, analysis, and interpretation of the data; preparation, review, or approval of the manuscript; or decision to submit the manuscript for publication. This study was supported by the Institute for Clinical Evaluative Sciences (ICES), which is funded by an annual grant from the Ontario Ministry of Health and Long-Term Care (MOHLTC). The opinions, results and conclusions reported in this paper are those of the authors and are independent from the funding sources. No endorsement by ICES or the Government of Ontario is intended or should be inferred. Parts of this material are based on data and information compiled and provided by the Canadian Institute for Health Information (CIHI). However, the analyses, conclusions, opinions, and statements expressed herein are those of the author, and not necessarily those of CIHI.

Licence for Publication: The Corresponding Author has the right to grant on behalf of all authors and does grant on behalf of all authors, an exclusive licence (or non exclusive for government employees) on a worldwide basis to the BMJ Publishing Group Ltd to permit this article (if accepted) to be published in JECH and any other BMJPGL products and sublicences such use and exploit all subsidiary rights, as set out in our licence (http://group.bmj.com/products/journals/instructions-for-authors/licence-forms).

Competing Interest: None declared. 


\section{References}

1. Admon LK, Winkelman TNA, Moniz MH, et al. Disparities in chronic conditions among women hospitalized for delivery in the United States, 2005-2014. Obstet Gynecol 2017;130(6):1319-26.

2. Kersten I, Lange AE, Haas JP, et al. Chronic diseases in pregnant women: prevalence and birth outcomes based on the SNiP-study. BMC Pregnancy Childbirth 2014;14:75.

3. United States Census Bureau. 2013-2017 American Community Survey 5-year estimates; 2017. [Internet]. [cited 2019 March 19] Available from: https://factfinder.census.gov/faces/tableservices/jsf/pages/productview.xhtml?src=bkmk

4. Shaw KM, Theis KA, Self-Brown S, Roblin DW, Barker L. Chronic disease disparities by county economic status and metropolitan classification, Behavioral Risk Factor Surveillance System, 2013. Preventing Chronic Disease 2016;13:E119.

5. Brown HK, Qazilbash A, Rahim N, Dennis CL, Vigod SN. Chronic medical conditions and peripartum mental illness: A systematic review and meta-analysis. Am J Epidemiol 2018;187(9):2060-68.

6. O'Hara MW, Swain AM. Rates and risk of postpartum depression-a meta-analysis. Int Rev Psychiatry 1996;8(1):37-54.

7. O'Hara MW, Wisner KL. Perinatal mental illness: definition, description and aetiology. Best Pract Res Clin Obstet Gynaecol 2014;28(1):3-12.

8. Deave T, Heron J, Evans J, Emond A. The impact of maternal depression in pregnancy on early child development. BJOG 2008;115(8):1043-51.

9. Meltzer-Brody S, Stuebe A. The long-term psychiatric and medical prognosis of perinatal mental illness. Best Pract Res Clin Obstet Gynaecol 2014;28(1):49-60. 
10. Dinca-Panaitescu S, Dinca-Panaitescu M, Bryant T, et al. Diabetes prevalence and income: Results of the Canadian Community Health Survey. Health Policy 2011;99(2):116-23.

11. Janzen B, Karunanayake C, Pahwa P, et al. Exploring diversity in socioeconomic inequalities in health among rural dwelling Canadians. J Rural Health 2015;31(2):186-98.

12. Rachele JN, Giles-Corti B, Turrell G. Neighbourhood disadvantage and self-reported type 2 diabetes, heart disease and comorbidity: a cross-sectional multilevel study. Ann Epidemiol 2016;26(2):146-50.

13. Morrissey K, Espuny F, Williamson P. A multinomial model for comorbidity in England of long-standing cardiovascular disease, diabetes and obesity. Health Soc Care Community 2016;24(6):717-27.

14. Squires D, Anderson C. U.S. health care from a global perspective: spending, use of services, prices, and health in 13 countries. Issue brief (Commonw Fund) 2015;15:1-15.

15. Fan AZ, Strasser SM, Zhang X, Fang J, Crawford CG. State socioeconomic indicators and self-reported hypertension among US adults, 2011 Behavioral Risk Factor Surveillance System. Prev Chronic Dis 2015;12:E27.

16. Akil L, Ahmad HA. Effects of socioeconomic factors on obesity rates in four southern states and Colorado. Ethnicity \& disease 2011;21(1):58-62. [published Online First: 2011/04/06]

17. Jamal A, Agaku IT, O'Connor E, et al. Current cigarette smoking among adults--United States, 2005-2013. MMWR Morbidity and mortality weekly report 2014;63(47):1108-12. [published Online First: 2014/11/27]

18. Estabrooks PA, Lee RE, Gyurcsik NC. Resources for physical activity participation: does availability and accessibility differ by neighborhood socioeconomic status? Ann Behav Med $2003 ; 25(2): 100-4$. 
19. Baker EA, Schootman M, Barnidge E, et al. The role of race and poverty in access to foods that enable individuals to adhere to dietary guidelines. Prev Chronic Dis 2006;3(3):A76.

20. Varekamp I, van Dijk FJ. Workplace problems and solutions for employees with chronic diseases. Occup Med 2010;60(4):287-93.

21. Goyal D, Gay C, Lee KA. How much does low socioeconomic status increase the risk of prenatal and postpartum depressive symptoms in first-time mothers? Womens Health Issues 2010;20(2):96-104.

22. Statistics Canada. CANSIM Table 102-4516: live births and fetal deaths (stillbirths) by place of birth (hospital and non-hospital), Canada, provinces and territories: annual; 2006. [Internet] [accessed 2019 May 8] Available from:

\section{https://www150.statcan.gc.ca/t1/tbl1/en/tv.action?pid=1310042901}

23. Williams JI, Young WA. Summary of studies on the quality of health care administrative databases in Canada. In: Goel V, Williams JI, Anderson GM, et al., eds. Patterns of Health Care in Ontario, The ICES Practice Atlas. Ottawa, ON: Canadian Medical Association; 1996:339-45.

24. Tu K, Campbell NR, Chen ZL, Chen ZL, Cauch-Dudek KJ, McAlister FA. Accuracy of administrative databases in identifying patients with hypertension. Open Med 2007;1(1):e1826.

25. Hux JE, Ivis F, Flintoft V, Bica A. Diabetes in Ontario: determination of prevalence and incidence using a validated administrative data algorithm. Diabetes Care 2002;25(3):512-6.

26. Gershon AS, Wang C, Guan J, et al. Identifying patients with physician-diagnosed asthma in health administrative databases. Can Respir J 2009;16(6):183-8. 
27. Mustard CA, Derksen S, Berthelot JM, Wolfson M. Assessing ecologic proxies for household income: a comparison of household and neighbourhood level income measures in the study of population health status. Health Place 1999;5(2):157-71.

28. Muldoon L, Rayner J, Dahrouge S. Patient poverty and workload in primary care: study of prescription drug benefit recipients in community health centres. Can Fam Physician 2013;59(4):384-90.

29. Kralj B. Measuring rurality - RIO2008 BASIC: methodology and results. Toronto, Ontario: Ontario Medical Association; 2009.

30. Zou G. A modified poisson regression approach to prospective studies with binary data. Am J Epidemiol 2004;159(7):702-6.

31. Zou GY, Donner A. Extension of the modified Poisson regression model to prospective studies with correlated binary data. Stat Method Med Res 2013;22(6):661-70.

32. Zou GY. On the estimation of additive interaction by use of the four-by-two table and beyond. Am J Epidemiol 2008;168(2):212-24.

33. Chapman DP, Perry GS, Strine TW. The vital link between chronic disease and depressive disorders. Prev Chronic Dis 2005;2(1):A14.

34. Van Lieshout RJ, Bienenstock J, MacQueen GM. A review of candidate pathways underlying the association between asthma and major depressive disorder. Psychosomatic Med 2009;71(2):187-95.

35. Kan C, Pedersen NL, Christensen K, Bornstein SR, Licinio J, MacCabe JH, et al. Genetic overlap between type 2 diabetes and depression in Swedish and Danish twin registries. Molecular Psych 2016;21(7):903-9. 
36. Cerda M, Diez-Roux AV, Tchetgen ET, Gordon-Larsen P, Kiefe C. The relationship between neighborhood poverty and alcohol use: estimation by marginal structural models. Epidemiology 2010;21(4):482-9. 
Table 1. Characteristics of the cohort according to presence of chronic medical conditions and poverty. Data presented as $\mathrm{n}(\%)$.

\begin{tabular}{|l|c|c|c|c|}
\hline Covariate & $\begin{array}{c}\text { Both CMC } \\
\text { and poverty } \\
(\mathbf{n = 4 2 , 6 4 0 )}\end{array}$ & $\begin{array}{c}\text { CMC only } \\
(\mathbf{n = 5 7 , 3 3 3 )}\end{array}$ & $\begin{array}{c}\text { Poverty only } \\
(\mathbf{n = 3 0 7 , 8 3 6})\end{array}$ & $\begin{array}{c}\text { Neither CMC } \\
\text { or poverty } \\
(\mathbf{n = 4 4 5 , 6 2 4})\end{array}$ \\
\hline Age (years) & & & & \\
\hline $15-24$ & $8,953(21.0)$ & $6,484(11.3)$ & $74,657(24.3)$ & $55,946(12.6)$ \\
\hline $25-34$ & $25,471(59.7)$ & $37,289(65.0)$ & $187,745(61.0)$ & $302,726(67.9)$ \\
\hline $35+$ & $8,216(19.3)$ & $13,560(23.7)$ & $45,434(14.8)$ & $86,952(19.5)$ \\
\hline Primiparous & $17,107(40.1)$ & $23,998(41.9)$ & $136,607(44.4)$ & $199,515(44.8)$ \\
\hline Rural residence & $2,123(5.0)$ & $2,364(4.1)$ & $15,550(5.1)$ & $17,843(4.0)$ \\
\hline Immigrant status & & & & \\
\hline \multicolumn{1}{|c|}{ Refugee } & $2,345(5.5)$ & $1,322(2.3)$ & $15,626(5.1)$ & $9,856(2.2)$ \\
\hline \multicolumn{1}{|c|}{ Immigrant } & $11,376(26.7)$ & $10,283(17.9)$ & $83,730(27.2)$ & $81,709(18.3)$ \\
\hline \multicolumn{1}{|c|}{ Long-term Resident } & $28,919(67.8)$ & $45,728(79.8)$ & $208,480(67.7)$ & $354,059(79.5)$ \\
\hline $\begin{array}{l}\text { Past history of mental } \\
\text { health care }\end{array}$ & $23,133(54.3)$ & $32,942(57.5)$ & $137,813(44.8)$ & $215,008(48.3)$ \\
\hline
\end{tabular}

Abbreviations: $\mathrm{CMC}=$ chronic medical conditions.

Note: poverty $=$ lowest two neighbourhood income quintiles. Excluded from this table are 4,571 individuals with missing information on poverty ( $0.5 \%$ of the total cohort). 
Table 2. Unadjusted and adjusted independent impact of chronic medical conditions and poverty on perinatal mental illness risk.

\begin{tabular}{|c|c|c|c|}
\hline Covariate & $\begin{array}{c}\text { N (\%) with } \\
\text { outcome }\end{array}$ & $\begin{array}{c}\text { Unadjusted RR } \\
(95 \% \mathrm{CI})\end{array}$ & $\begin{array}{c}\text { Adjusted RR } \\
(95 \% \mathrm{CI})\end{array}$ \\
\hline \multicolumn{4}{|l|}{ Chronic medical conditions } \\
\hline 1 or more conditions & $19,783(19.7)$ & $1.25(1.24,1.27)$ & $1.21(1.20,1.23)$ \\
\hline No conditions & $117,745(15.5)$ & 1.00 (Reference) & 1.00 (Reference) \\
\hline \multicolumn{4}{|l|}{ Poverty } \\
\hline Bottom 2 income quintiles & $58,659(16.7)$ & $1.07(1.06,1.08)$ & $1.06(1.05,1.07)$ \\
\hline Top 3 income quintiles & $78,177(15.5)$ & 1.00 (Reference) & 1.00 (Reference) \\
\hline \multicolumn{4}{|l|}{ Age (years) } \\
\hline $15-24$ & $30,348(20.5)$ & $1.34(1.33,1.36)$ & $1.35(1.34,1.37)$ \\
\hline $25-34$ & $83,965(15.1)$ & 1.00 (Reference) & 1.00 (Reference) \\
\hline $35+$ & $23,215(15.0)$ & $0.99(0.97,0.998)$ & $0.97(0.96,0.99)$ \\
\hline \multicolumn{4}{|l|}{ Parity } \\
\hline Primiparous & $66,634(17.6)$ & $1.15(1.14,1.16)$ & $1.15(1.14,1.16)$ \\
\hline Multiparous & $70,891(14.8)$ & 1.00 (Reference) & 1.00 (Reference) \\
\hline \multicolumn{4}{|l|}{ Rural resident } \\
\hline Rural & $5,645(14.8)$ & $0.93(0.90,0.95)$ & $0.86(0.84,0.88)$ \\
\hline Urban & $130,219(16.1)$ & 1.00 (Reference) & 1.00 (Reference) \\
\hline \multicolumn{4}{|l|}{ Immigrant Status } \\
\hline Refugee & $4,260(14.6)$ & $0.86(0.83,0.88)$ & $0.92(0.89,0.94)$ \\
\hline Immigrant & $24,574(13.1)$ & $0.77(0.76,0.78)$ & $0.90(0.88,0.91)$ \\
\hline Long-term Resident & $108,694(17.0)$ & 1.00 (Reference) & 1.00 (Reference) \\
\hline \multicolumn{4}{|l|}{ Past history of mental health care } \\
\hline Past history & $84,660(20.6)$ & $1.70(1.69,1.72)$ & $1.72(1.70,1.74)$ \\
\hline No Past history & $52,868(11.8)$ & 1.00 (Reference) & 1.00 (Reference) \\
\hline
\end{tabular}

Abbreviations: $\mathrm{CI}=$ confidence interval; $\mathrm{RR}=$ relative risk. 
Figure 1. Derivation of the study cohort

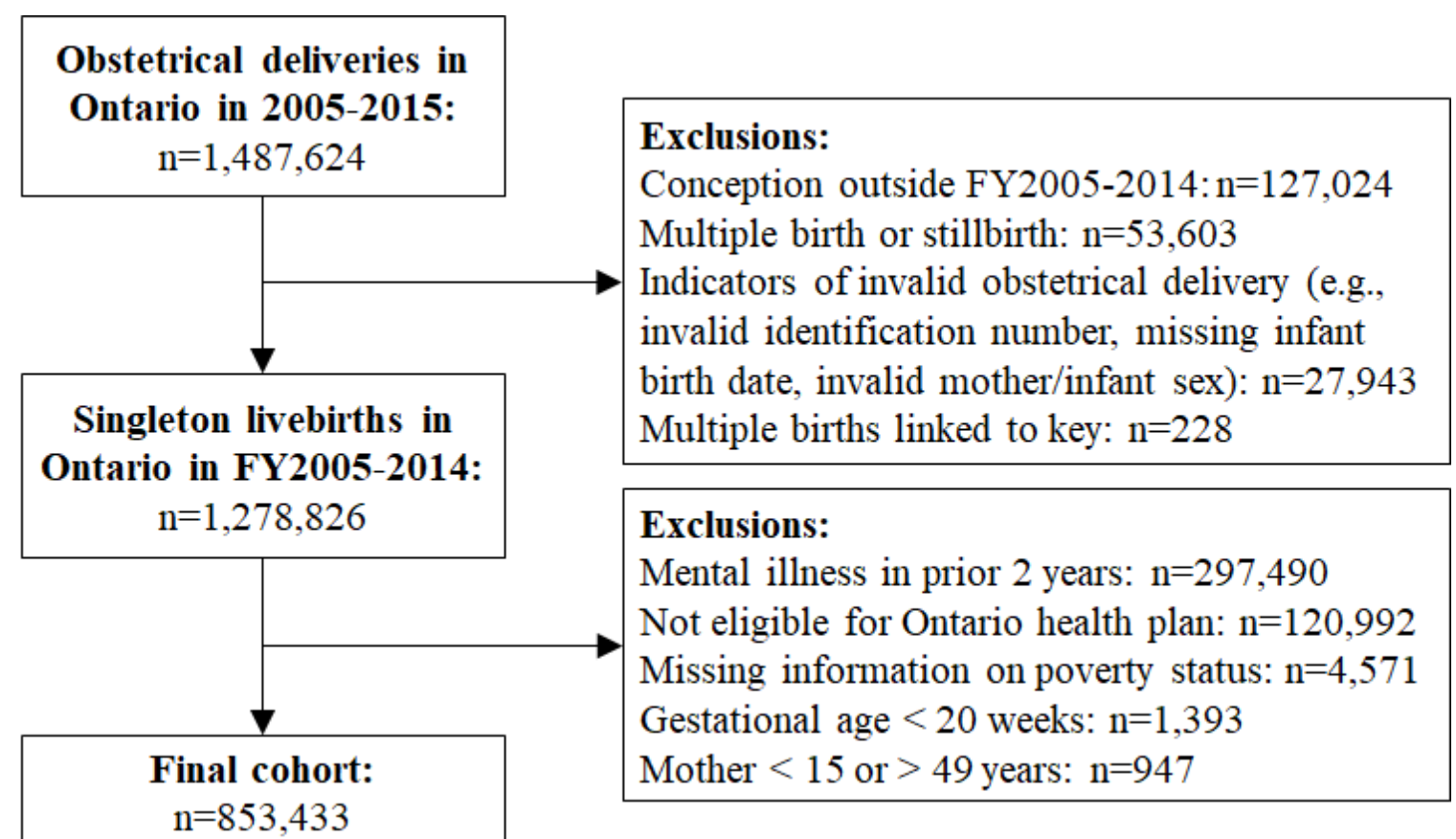


Figure 2. Impacts of chronic medical conditions and poverty on perinatal mental illness risk. Data presented as $\mathrm{n}(\%)$ with the outcome and adjusted relative risk (aRR) and 95\% confidence interval (CI), adjusted for maternal age, parity, rural residence, immigrant status, and past history of mental health care.

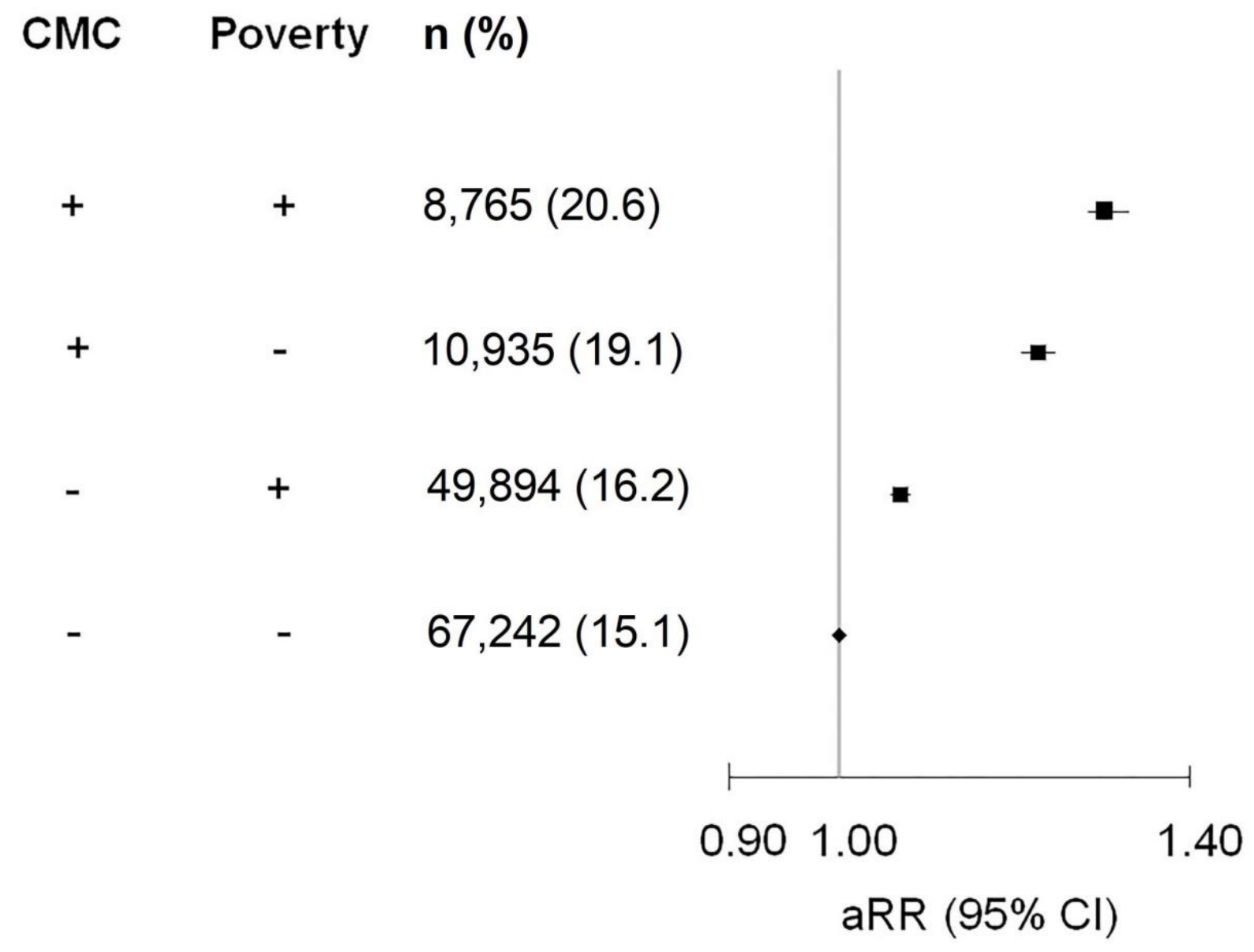


Table S1. Algorithms used to identify chronic medical conditions.

\begin{tabular}{|c|c|c|c|}
\hline $\begin{array}{c}\text { Chronic medical } \\
\text { condition }\end{array}$ & Algorithm ${ }^{a, b}$ & $\begin{array}{c}\text { Validity vs. clinical } \\
\text { diagnosis }\end{array}$ & Validation study \\
\hline Hypertension & $\begin{array}{l}\text { One hospitalization (ICD-9: 401-405; ICD: I10, I11, } \\
\text { I12, I13, I15) or one physician visit (OHIP: 401, } \\
\text { 402, 403, 404, 405) followed by an additional } \\
\text { physician visit or hospitalization within } 2 \text { years. }\end{array}$ & $\begin{array}{l}\text { Sensitivity: } 73 \% \\
\text { Specificity: } 95 \%\end{array}$ & $\begin{array}{l}\text { Tu K, Campbell NR, Chen ZL, Cauch-Dudek KJ, } \\
\text { McAlister FA. Accuracy of administrative databases } \\
\text { in identifying patients with hypertension. Open Med } \\
\text { 2007;1(1):e18-26. }\end{array}$ \\
\hline \multirow[t]{4}{*}{$\begin{array}{l}\text { Cardiovascular } \\
\text { disease }\end{array}$} & $\begin{array}{l}\text { Atrial fibrillation: Four physician visits (OHIP: 427) } \\
\text { (separated by } 30 \text { days) or one hospitalization or } \\
\text { emergency department visit (ICD-9: } 427.3 \text {; ICD-10: } \\
\text { I48.0) in } 1 \text { year. }\end{array}$ & $\begin{array}{l}\text { Sensitivity: } 97 \% \\
\text { Positive predictive } \\
\text { value: } 93 \%\end{array}$ & $\begin{array}{l}\text { Tu K, Nieuwlaat R, Cheng SY, Wing L, Ivers N, } \\
\text { Atzema CL, et al. Identifying patients with atrial } \\
\text { fibrillation in administrative data. Can J Cardiol } \\
\text { 2016;32(12):1561-5. }\end{array}$ \\
\hline & $\begin{array}{l}\text { Congestive heart failure: One physician visit } \\
\text { (OHIP: } 428 \text { or feecode Q050) or one hospitalization } \\
\text { or emergency department visit (ICD-9: } 428 \text {; ICD- } \\
\text { 10: I50.0, I50.1, I50.9) followed by a second record } \\
\text { from either source in } 1 \text { year. }\end{array}$ & $\begin{array}{l}\text { Sensitivity: } 85 \% \\
\text { Specificity: } 97 \%\end{array}$ & $\begin{array}{l}\text { Schultz SE, Rothwell DM, Chen Z, Tu K. } \\
\text { Identifying cases of congestive heart failure from } \\
\text { administrative data: a validation study using primary } \\
\text { care patient records. Chron Dis Inj Can } \\
\text { 2013;33(3):160-6. }\end{array}$ \\
\hline & $\begin{array}{l}\text { Myocardial infarction: One hospitalization (ICD-9: } \\
\text { 410; ICD-10: I21) in } 5 \text { years. }\end{array}$ & $\begin{array}{l}\text { Sensitivity: } 89 \% \\
\text { Specificity: } 93 \%\end{array}$ & $\begin{array}{l}\text { Austin PC, Daly PA, Tu JV. A multicenter study of } \\
\text { the coding accuracy of hospital discharge } \\
\text { administrative data for patients admitted to cardiac } \\
\text { care units in Ontario. Am Heart J 2002;144(2):290-6. }\end{array}$ \\
\hline & $\begin{array}{l}\text { Stroke or transient ischemic attack: Two physician } \\
\text { visits (OHIP: 432, 435, 436) or one hospitalization } \\
\text { or emergency department visit (ICD-9: 362.3, 430, } \\
\text { 431, 434.x, 435.x, 436; ICD-10: I60.x, I61.x, I63.x } \\
\text { except I63.6, I64, H34.0, H34.1, G45.x except } \\
\text { G45.4) in 1 year. }\end{array}$ & $\begin{array}{l}\text { Sensitivity: } 68 \% \\
\text { Specificity: } 98 \%\end{array}$ & $\begin{array}{l}\text { Tu K, Wang M, Young J, Green D, Ivers NM, Butt } \\
\mathrm{D} \text {, et al. Validity of administrative data for } \\
\text { identifying patients who have had a stroke or } \\
\text { transient ischemic attack using EMRALD as a } \\
\text { reference standard. Can J Cardiol 2013;29(11):1388- } \\
94 \text {. }\end{array}$ \\
\hline $\begin{array}{l}\text { Type } 1 \text { or type } 2 \\
\text { diabetes }\end{array}$ & $\begin{array}{l}\text { If }<19 \text { years: Four physician visits (OHIP: } 250 \text { or } \\
\text { feecode Q040, K029, K030, K045, K046) within } 2 \\
\text { years and at least } 1 \text { of these (OHIP: } 250) \text { before } 19^{\text {th }} \\
\text { birthday, in } 2 \text { years. If } \geq 19 \text { years: Two physician } \\
\text { visits (OHIP: } 250 \text { ) or one procedure (Q040, K029, } \\
\text { K030, K045, K046) or one hospitalization (ICD-9: } \\
\text { 250; ICD-10: E10, E11, E13, E14) in } 2 \text { years. }\end{array}$ & $\begin{array}{l}\text { Sensitivity: } 86 \% \\
\text { Specificity: } 97 \%\end{array}$ & $\begin{array}{l}\text { Hux JE, Ivis F, Flintoft V, Bica A. Diabetes in } \\
\text { Ontario: determination of prevalence and incidence } \\
\text { using a validated administrative data algorithm. } \\
\text { Diabetes Care 2002;25(3):512-6. }\end{array}$ \\
\hline Thyroid disease & $\begin{array}{l}\text { Two physician visits (OHIP: 242, 244) or one } \\
\text { hospitalization or emergency department visit (ICD- } \\
\text { 9: } 242,244 \text {; ICD-10: E00, E03, E05) in } 2 \text { years. }\end{array}$ & Not stated & $\begin{array}{l}\text { Frost L, Vestergaard P, Mosekilde L. } \\
\text { Hyperthyroidism and risk of atrial fibrillation or } \\
\text { flutter: a population-based study. Arch Int Med } \\
2004 ; 164(15): 1675-8 \text {. }\end{array}$ \\
\hline
\end{tabular}




\begin{tabular}{|c|c|c|c|}
\hline $\begin{array}{l}\text { Chronic medical } \\
\text { condition }\end{array}$ & Algorithm $^{\text {a, b }}$ & $\begin{array}{c}\text { Validity vs. clinical } \\
\text { diagnosis }\end{array}$ & Validation study \\
\hline Asthma & $\begin{array}{l}\text { Two physician visits (OHIP: 493) or one } \\
\text { hospitalization (ICD-9: 493; ICD-10: J45, J46) in } 2 \\
\text { years. }\end{array}$ & $\begin{array}{l}\text { Sensitivity: } 84 \% \\
\text { Specificity: } 77 \%\end{array}$ & $\begin{array}{l}\text { Gershon AS, Wang C, Guan J, Vasilevska-Ristovska } \\
\text { J, Cicutto L, To T. Identifying patients with } \\
\text { physician-diagnosed asthma in health administrative } \\
\text { databases. Can Resp J 2009;16(6):183-8. }\end{array}$ \\
\hline $\begin{array}{l}\text { Chronic obstructive } \\
\text { pulmonary disease }\end{array}$ & $\begin{array}{l}\text { One physician visit (OHIP: 491, 492, 496) or one } \\
\text { hospitalization (ICD-9: 491, 492, 496; ICD-10: J41, } \\
\text { J42, J43, J44) in } 3 \text { years. }\end{array}$ & $\begin{array}{l}\text { Sensitivity: } 85 \% \\
\text { Specificity: } 78 \%\end{array}$ & $\begin{array}{l}\text { Gershon AS, Wang C, Guan J, Vasilevska-Ristovska } \\
\text { J, Cicutto L, To T. Identifying individuals with } \\
\text { physcian diagnosed COPD in health administrative } \\
\text { databases. COPD 2009;6(5):388-94. }\end{array}$ \\
\hline Osteoarthritis & $\begin{array}{l}\text { Two physician visits (OHIP: 715) or one } \\
\text { hospitalization or emergency department visit (ICD- } \\
\text { 9: 715; ICD-10: M16-19) in } 2 \text { years. }\end{array}$ & Not stated & $\begin{array}{l}\text { Mondor L, Maxwell CJ, Bronskill SE, Gruneir A, } \\
\text { Wodchis WP. The relative impact of chronic } \\
\text { conditions and multimorbidity on health-related } \\
\text { quality of life in Ontario long-stay home care clients. } \\
\text { Qual Life Res 2016;25(10):2619-32. }\end{array}$ \\
\hline Osteoporosis & $\begin{array}{l}\text { One physician visit (OHIP: 733) or one } \\
\text { hospitalization or emergency department visit (ICD- } \\
\text { 9: 733.0; ICD-10: M80-82) in } 2 \text { years. }\end{array}$ & $\begin{array}{l}\text { Sensitivity: } 98 \% \\
\text { Specificity: } 93 \%\end{array}$ & $\begin{array}{l}\text { Cadarette SM, Jaglal SB, Raman-Wilms L, Beaton } \\
\text { DE, Paterson JM. Osteoporosis quality indicators } \\
\text { using healthcare utilization data. Osteoporosis Int } \\
\text { 2011;22(5):1335-42. }\end{array}$ \\
\hline Rheumatoid arthritis & $\begin{array}{l}\text { Three physician visits (OHIP: 714) with one or } \\
\text { more by a specialist (rheumatologist, internal } \\
\text { medicine specialist, orthopedic surgeon) or one } \\
\text { hospitalization or emergency department visit (ICD- } \\
\text { 9: 714; ICD-10: M05, M06) in } 2 \text { years. }\end{array}$ & $\begin{array}{l}\text { Sensitivity } 78 \% \\
\text { Specificity } 100 \%\end{array}$ & $\begin{array}{l}\text { Widdifield J, Bombardier C, Bernatsky S, Paterson } \\
\text { JM, Green D, Young J, et al. An administrative data } \\
\text { validation study of the accuracy of algorithms for } \\
\text { identifying rheumatoid arthritis: the influence of the } \\
\text { reference standard on algorithm performance. BMC } \\
\text { Musc Disord 2014;15:216. }\end{array}$ \\
\hline $\begin{array}{l}\text { Inflammatory bowel } \\
\text { disease }\end{array}$ & $\begin{array}{l}\text { Two years of OHIP eligibility and five physician } \\
\text { visits (OHIP: 555, 556) or hospitalizations or } \\
\text { emergency department visits (ICD-9: 555, 556; } \\
\text { ICD-10: K50, K51) OR < } 2 \text { years of OHIP } \\
\text { eligibility and three physician visits (OHIP: 555, } \\
\text { 556) or hospitalizations or emergency department } \\
\text { visits (ICD-9: 555, 556; ICD-10: K50, K51), in } 4 \\
\text { years. }\end{array}$ & $\begin{array}{l}\text { Sensitivity } 77 \% \\
\text { Specificity } 96 \% .\end{array}$ & $\begin{array}{l}\text { Benchimol EI, Guttmann A, Mack DR, Nguyen GC, } \\
\text { Marshall JK, Gregor JC, et al. Validation of } \\
\text { international algorithms to identify adults with } \\
\text { inflammatory bowel disease in health administrative } \\
\text { data from Ontario, Canada. J Clin Epidemiol } \\
\text { 2014;67(8):887-96. }\end{array}$ \\
\hline $\begin{array}{l}\text { Chronic kidney } \\
\text { disease }\end{array}$ & $\begin{array}{l}\text { One physician visit (OHIP: 403, 585) or } \\
\text { hospitalization (ICD-9: 403.0, 403.1, 403.9, 404.0, } \\
\text { 404.1, 404.9, 580-587, 5880, 588.8, 588.9, 593.7; } \\
\text { ICD-10: E10.2, E11.2, E13.2, E14.2, I12, I13, N08, } \\
\text { N18, N19) in 5 years. }\end{array}$ & $\begin{array}{l}\text { Positive predictive } \\
\text { value: } 85 \% \\
\text { Negative predictive } \\
\text { value: } 68 \%\end{array}$ & $\begin{array}{l}\text { Fleet JL, Dixon SN, Shariff SZ, Quinn RR, Nash } \\
\text { DM, Harel Z, et al. Detecting chronic kidney disease } \\
\text { in population-based administrative databases using } \\
\text { an algorithm of hospital encounter and physician } \\
\text { claim codes. BMC Nephrology 2013;14:81. }\end{array}$ \\
\hline
\end{tabular}




\begin{tabular}{|c|c|c|c|}
\hline $\begin{array}{c}\text { Chronic medical } \\
\text { condition }\end{array}$ & Algorithm $^{\text {a, b }}$ & $\begin{array}{c}\text { Validity vs. clinical } \\
\text { diagnosis }\end{array}$ & Validation study \\
\hline Multiple sclerosis & $\begin{array}{l}\text { Five physician visits (OHIP: 340) or one } \\
\text { hospitalization or emergency department visit (ICD- } \\
\text { 9: 340; ICD-10: G35.x) in } 2 \text { years. }\end{array}$ & $\begin{array}{l}\text { Sensitivity: } 84 \% \\
\text { Positive predictive } \\
\text { value: } 86 \%\end{array}$ & $\begin{array}{l}\text { Widdifield J, Ivers NM, Young J, Green D, } \\
\text { Jaakkimainen L, Butt DA, et al. Development and } \\
\text { validation of an administrative data algorithm to } \\
\text { estimate the disease burden and epidemiology of } \\
\text { multiple sclerosis in Ontario, Canada. Multiple } \\
\text { Sclerosis 2015;21(8):1045-54. }\end{array}$ \\
\hline Epilepsy & $\begin{array}{l}\text { Three physician visits separated by at least } 30 \text { days } \\
\text { (OHIP: } 345 \text { ) or one hospitalization (ICD-9: } 345 . x \\
\text { except } 345.2 \text { and } 345.3 \text {; ICD-10: G40) in } 2 \text { years. }\end{array}$ & $\begin{array}{l}\text { Sensitivity: } 74 \% \\
\text { Specificity: } 99 \%\end{array}$ & $\begin{array}{l}\text { Tu K, Wang M, Jaakkimainen RL, Butt D, Ivers } \\
\text { NM, Young J, et al. Assessing the validity of using } \\
\text { administrative data to identify patients with epilepsy. } \\
\text { Epilepsia 2014;55(2):335-43. }\end{array}$ \\
\hline Chronic migraine & $\begin{array}{l}\text { Two or more physician visits (OHIP: 346) or one or } \\
\text { more hospitalization or emergency department visit } \\
\text { (ICD-9: 307.8, 346, 349, 627.2, 784; ICD-10: G43, } \\
\text { G44, G97.1, N95.1, R51) in 2 years. }\end{array}$ & Not stated & $\begin{array}{l}\text { van Walraven C, Colman I. Migraineurs were } \\
\text { reliably identified using administrative data. J Clin } \\
\text { Epidemiol 2016;71:68-75. }\end{array}$ \\
\hline Lupus & $\begin{array}{l}\text { Three physician visits (OHIP: 710) with one or } \\
\text { more by a specialist (rheumatologist) or one } \\
\text { hospitalization (ICD-9: 710.0; ICD-10: M32) in } 2 \\
\text { years. }\end{array}$ & Not stated & $\begin{array}{l}\text { Bernatsky S, Joseph L, Pineau CA, Tamblyn R, } \\
\text { Feldman DE, Clarke AE. A population-based } \\
\text { assessment of systemic lupus erythematosus } \\
\text { incidence and prevalence--results and implications of } \\
\text { using administrative data for epidemiological } \\
\text { studies. Rheumatology 2007;46(12):1814-8. }\end{array}$ \\
\hline Psoriasis & $\begin{array}{l}\text { One physician visit (OHIP: 696) or hospitalization } \\
\text { (ICD-9: 696.0, 696.1; ICD-10: L40) in } 3 \text { years. }\end{array}$ & $\begin{array}{l}\text { Sensitivity: } 71 \% \\
\text { Specificity: } 97 \%\end{array}$ & $\begin{array}{l}\text { Eder L WJ, Rosen CF, Gladman DD, Alhusayen R, } \\
\text { Paterson M, et al. Accuracy of Canadian } \\
\text { administrative health data in identifying patients with } \\
\text { psoriasis and psoriatic arthritis using primary care } \\
\text { medical records as the reference standard. } \\
\text { ACR/ARHP Annual Meeting; } 2017 \text {. }\end{array}$ \\
\hline
\end{tabular}

${ }^{a}$ Where multiple physician visits, emergency department visits or hospitalizations were required during the lookback period, we required only one to occur before conception as long as the second occurred within the algorithm's required length of time from the first encounter.

$\mathrm{b}$ The lookback periods were chosen based on the results of the algorithm validation studies. Women with CMC diagnoses outside of the lookback period (e.g., those with childhood asthma, or with hypertension subsequently resolved through diet or weight loss) would be classified as not having CMC. The choice to focus on "active" CMC is reasonable since it is such conditions that are most likely to impact perinatal mental health and that are of relevance for screening and treatment purposes. 
Figure S1. Impacts of chronic medical conditions and poverty on perinatal mental illness risk, by timing of perinatal mental illness. Data presented as $\mathrm{n}(\%)$ with the outcome and adjusted relative risk (aRR) and 95\% confidence interval (CI), adjusted for maternal age, parity, rural residence, immigrant status, and past history of mental health care. Blue $=$ prenatal mental illness, purple $=$ postnatal mental illness.

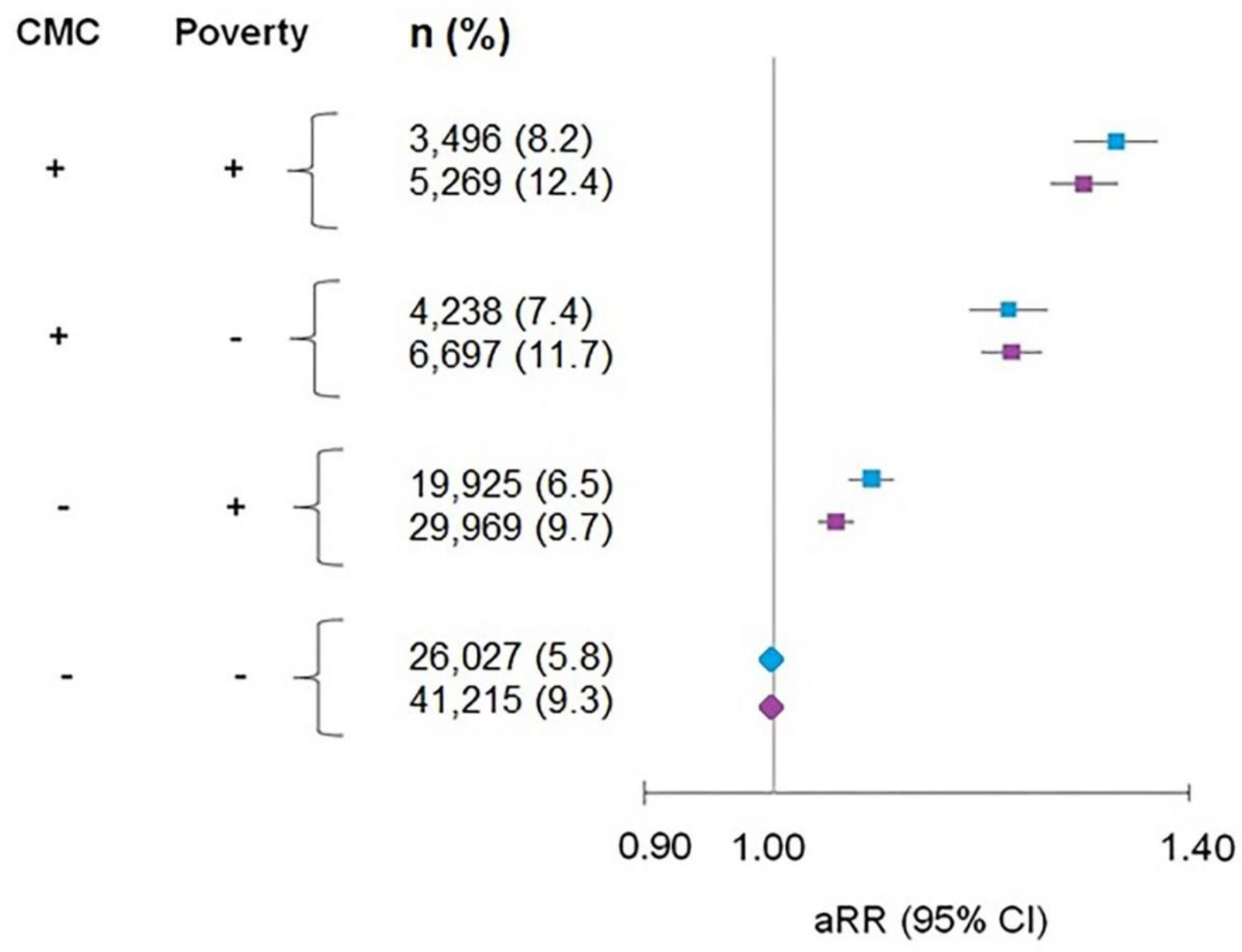


Figure S2. Impacts of chronic medical conditions and poverty on perinatal mental illness risk, by diagnosis of perinatal mental illness. Data presented as $\mathrm{n}(\%)$ with the outcome and adjusted relative risk (aRR) and 95\% confidence interval (CI), adjusted for maternal age, parity, rural residence, immigrant status, and past history of mental health care. Blue = mental health disorder, purple $=$ substance use disorder.

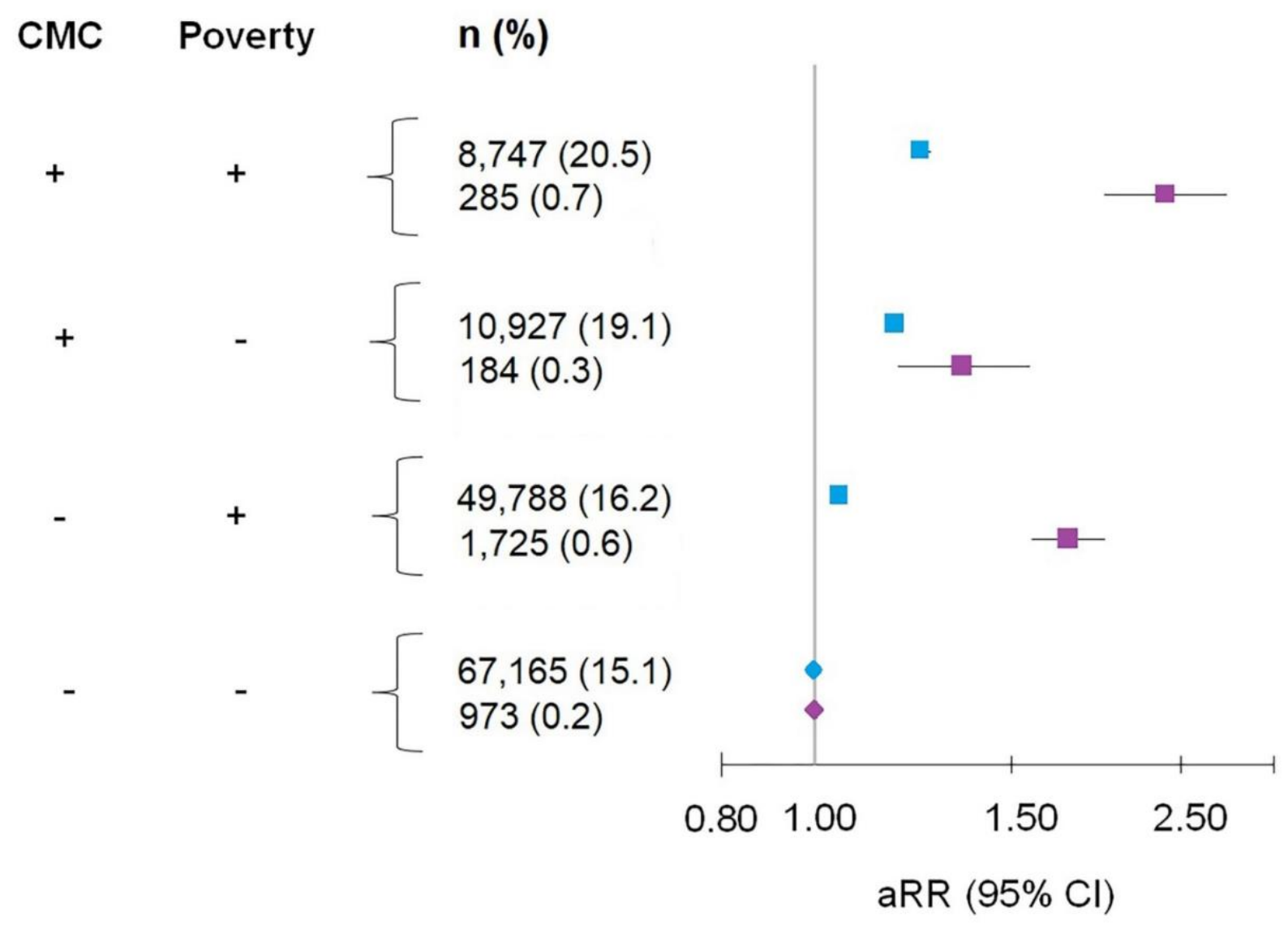


Figure S3. Impacts of chronic medical conditions and poverty on perinatal mental illness risk, by type of mental health care contact. Data presented as $n(\%)$ with the outcome and adjusted relative risk (aRR) and 95\% confidence interval (CI), adjusted for maternal age, parity, rural residence, immigrant status, and past history of mental health care. Blue = ambulatory care visit, purple $=$ acute care visit.

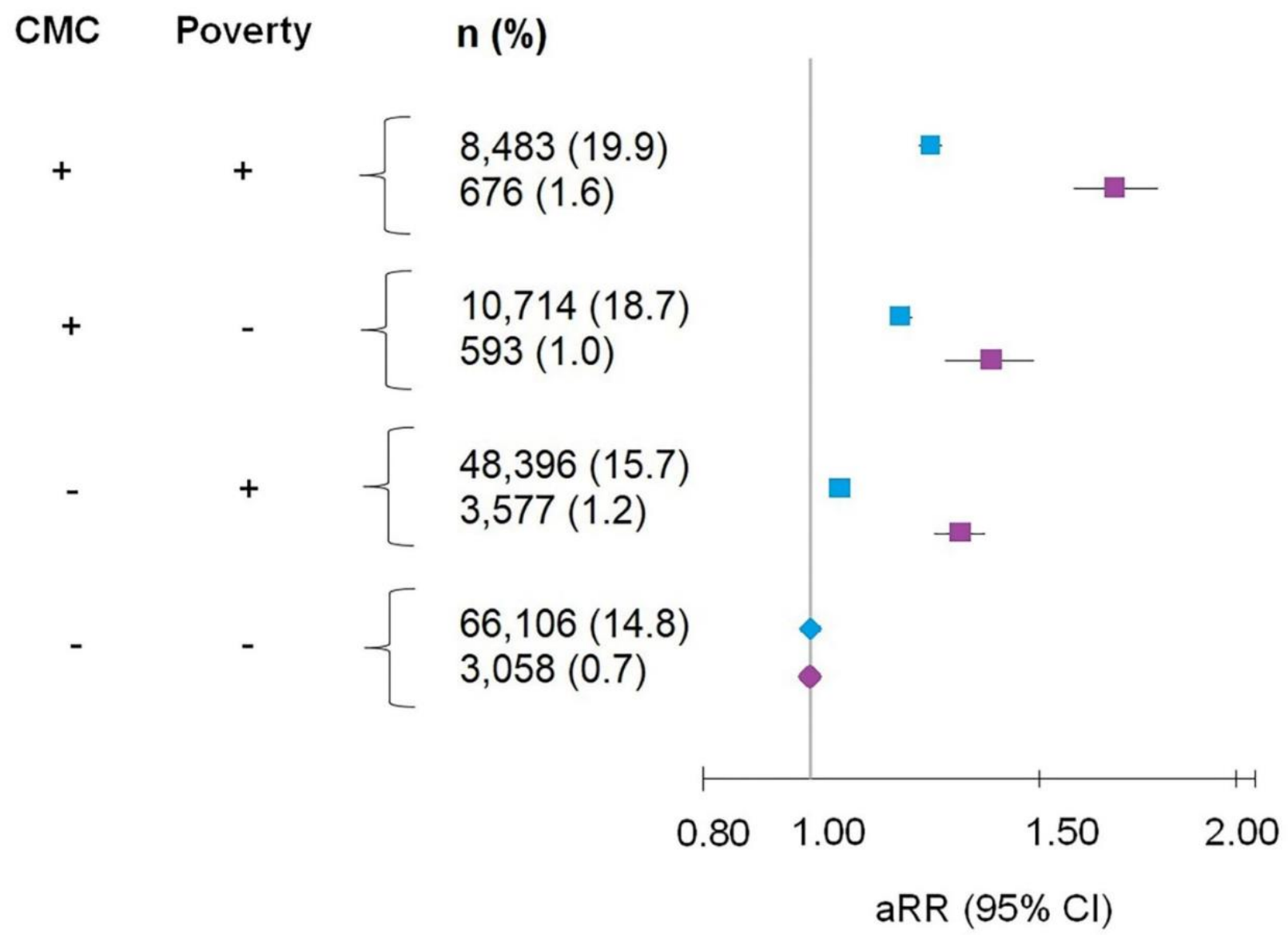


Figure S4. Impacts of chronic medical conditions and poverty on perinatal mental illness risk, by number of chronic medical conditions. Data presented as $\mathrm{n}(\%)$ with the outcome and adjusted relative risk (aRR) and 95\% confidence interval (CI), adjusted for maternal age, parity, rural residence, immigrant status, and past history of mental health care. Blue $=$ two or more chronic medical conditions, purple $=$ one chronic medical condition, orange $=$ no chronic medical conditions.

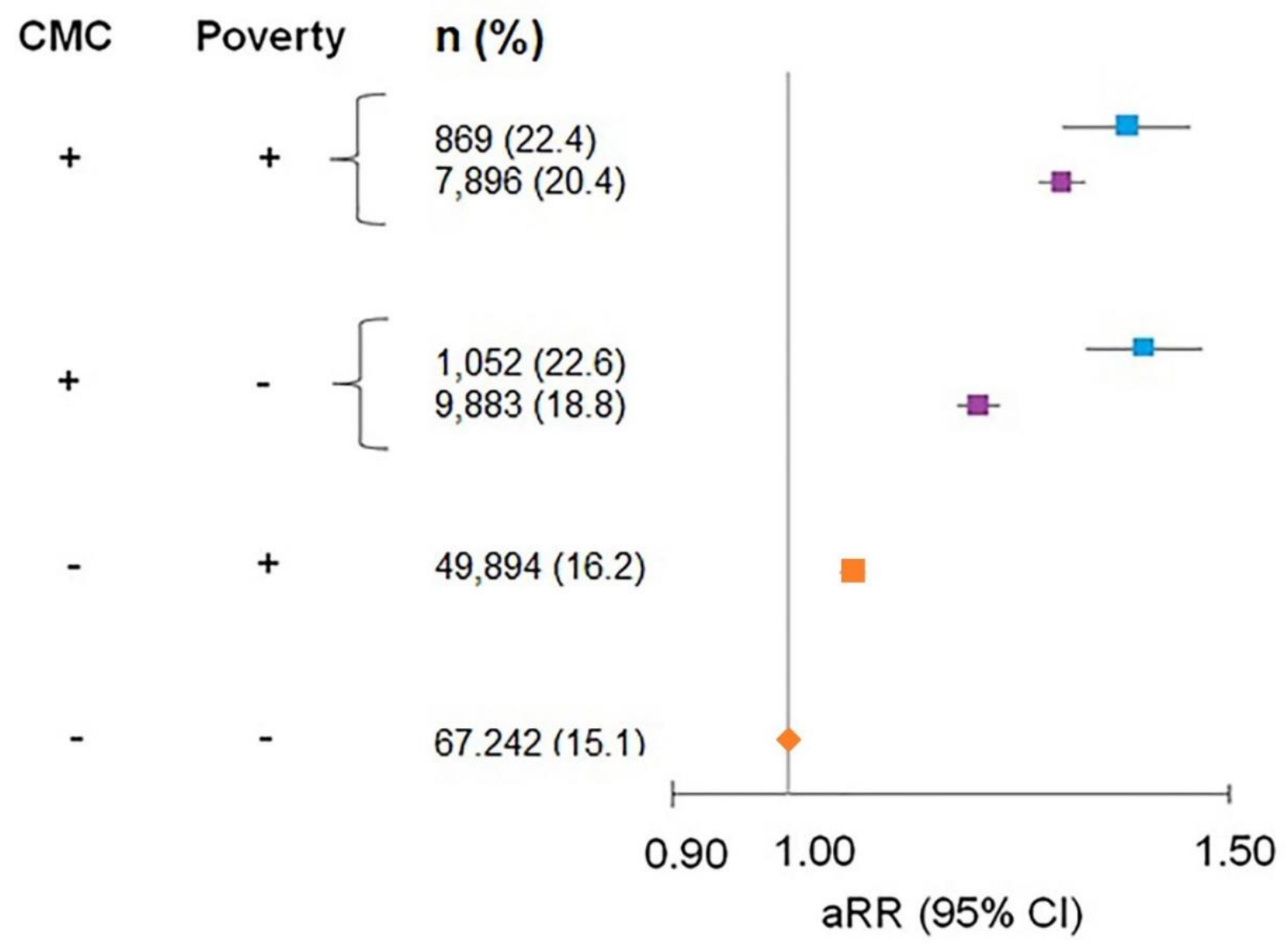


Figure S5. Impacts of chronic medical conditions and poverty, lowest income quintile versus others, on perinatal mental illness risk. Data presented as $\mathrm{n}(\%)$ with the outcome and adjusted relative risk (aRR) and 95\% confidence interval (CI), adjusted for maternal age, parity, rural residence, immigrant status, and past history of mental health care.

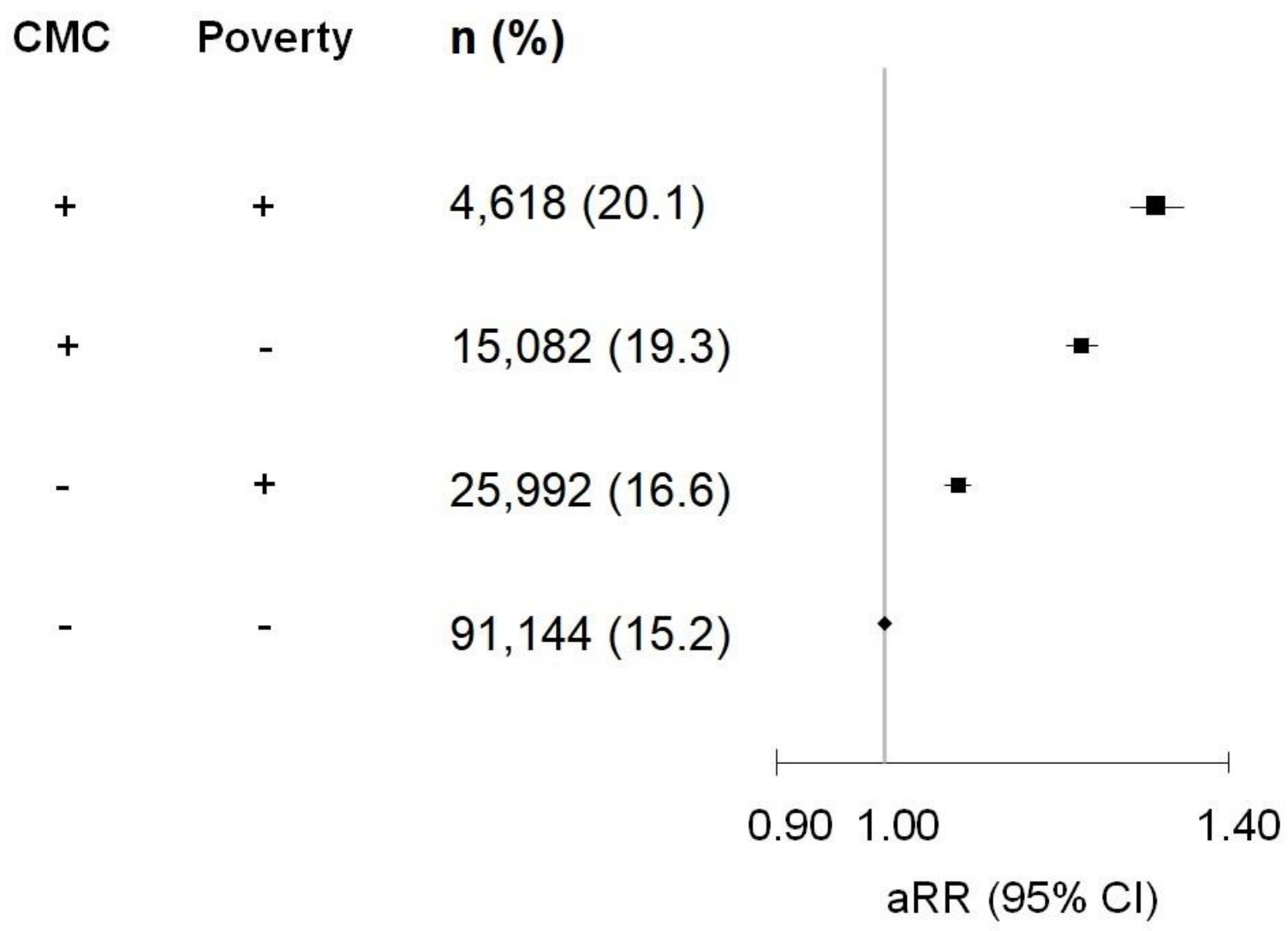


Figure S6. Impacts of chronic medical conditions and poverty, across all income quintiles, on perinatal mental illness risk. Data presented as adjusted relative risk (aRR) and 95\% confidence interval (CI), adjusted for maternal age, parity, rural residence, immigrant status, and past history of mental health care. Blue = quintile 1 (lowest), purple $=$ quintile 2 , orange $=$ quintile 3 , green $=$ quintile 4 , red $=$ quintile 5 (highest).

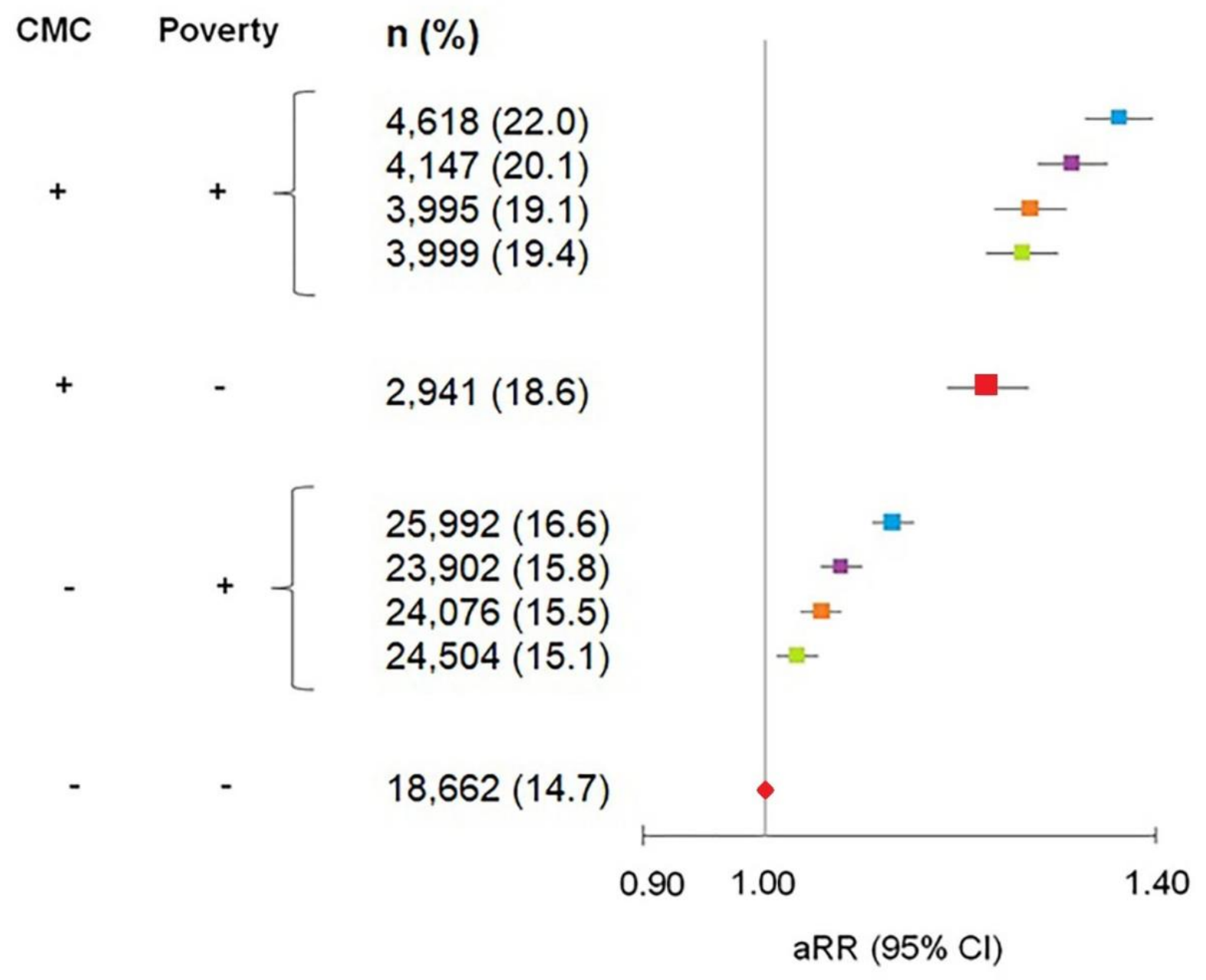

